Resenha 


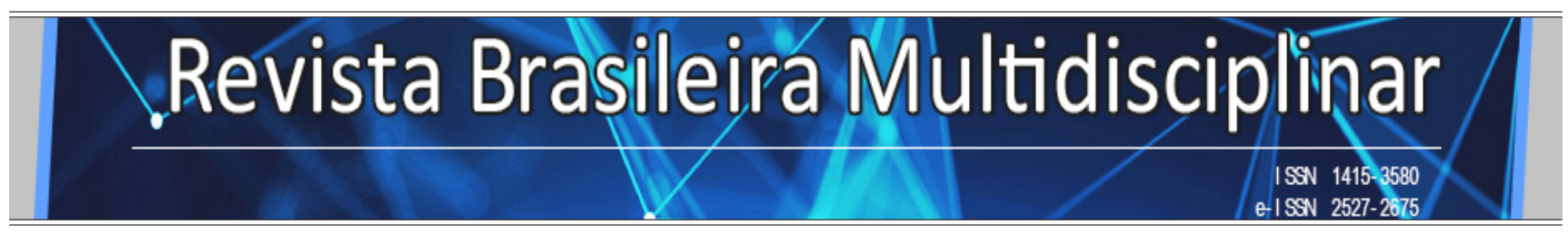

http://revistarebram.com/index.php/revistauniara

\section{A EDUCAÇÃo EM DEBATE: ESCOLA, INFÂNCIA E SEXUALIDADE}

Emerson Benedito Ferreira*; Mario Marcos Lopes ${ }^{\star *}$

${ }^{*}$ Mestre e Doutorando em Educação pela Universidade Federal de São Carlos (bolsista CNPq). Especialista em Direito Educacional e Filosofia da Educação pela FESL.

${ }^{*}$ Mestre em Desenvolvimento Regional e Meio Ambiente pelo Universidade de Araraquara. Especialista na área educacional. Docente do Centro Universitário Barão de Mauá; Faculdade de Educação São Luís. Professor Coordenador da Rede Estadual de Ensino de São Paulo.

${ }^{*}$ Autor para correspondência e-mail: em@gmail.com

\section{Palavras-Chave}

Educação

Infantil

Sexualidade

\section{KEYWORDS}

Education

Child

Sexuality

\section{RESUMO}

A presente resenha tem como objetivo apresentar uma reflexão crítica da obra "Pesquisas em educação: escola, infância e sexualidade", obra esta que se esforça para propiciar à temática educacional um enfoque interdisciplinar. Neste contexto, os organizadores selecionaram pesquisas das mais variadas áreas da educação para uma necessária e abrangente intersecção entre escola, infância e sexualidade. Deste modo redes sociais, disciplina, escolas cristãs, brincar, lúdico, literatura infantil, genealogia da infância, direito e educação, violência sexual, gênero e sexualidade são abordados e trabalhados de forma irrestrita para que a educação se faça presente não só como uma questão meramente reservada ao ambiente escolar, mas sim, que sirva como instrumento possibilitador de mudanças reais para toda a sociedade.

\begin{abstract}
RESEARCH IN EDUCATION: SCHOOL, CHILDHOOD AND SEXUALITY

This review aims to present a critical reflection of the work "research in education: school, childhood and sexuality"a work that strives to provide an interdisciplinary approach to education. In this context, the organizers selected research from a wide range of areas of education for a necessary and comprehensive intersection between school, childhood and sexuality. In this way social networks, discipline, christian schools, play, playful, children's literature, children's genealogy, law and education, sexual violence, gender and sexuality are approached and worked in an unrestricted way so that education becomes present not only as an issue Merely reserved for the school environment, but rather serves as an enabling instrument for real changes for the whole society.
\end{abstract}




\section{INTRODUÇÃo}

Pesquisas em educação: escola, infância e sexualidade é uma importante reflexão, organizada pelos pesquisadores Emerson Benedito Ferreira e Mario Marcos Lopes que com a ajuda de outros colaboradores debatem o tema educação em suas mais variadas formas de atuação, com enfoque na temática escola, infância e sexualidade. A obra reúne pesquisas de especialistas, mestres e doutores que abordam a temática de uma forma rica e aprofundada, levando o leitor a uma visão ampla da dimensão educacional.

No primeiro capítulo do livro - A sociedade insone e a formação humana na era dos cliques a autora Ana Helena Ribeiro Garcia de Paiva Lopes aponta a acomodação dos indivíduos em viver em uma sociedade insone que não os permitem parar e contemplar a criatividade que emerge do ócio, naturaliza-se o absurdo, decorrência da semiformação generalizada que assola a humanidade, tão, contraditoriamente, desfeita de seus caracteres humanos. O enrijecimento do eu na relação com o outro externa a consequência de indivíduos semiformados e insuflados pela Indústria Cultural a consumir, emitir e exibir compulsivamente como modo de alcançar a tão almejada felicidade e o tão requerido status de ser. Nesse enredo, as redes sociais se apresentam como palco para livre expressão em notórias manifestações regressivas de um espetáculo fúnebre do eu semiformado. Nota-se que neste artigo, a autora objetiva explicitar o necessário diálogo entre o campo educacional e as tecnologias digitais, com especial atenção para as redes sociais, considerando-se a relação potencializada do uso de tais redes como um dos grandes desafios contemporâneos da Educação

No capítulo 2 as autoras Lidiane Maria Fávero e Senhorinha de Fátima Reis Arruda com o texto Educação, disciplina e comportamento nas escolas cristãs de João Batista de La Salle, buscam apresentar alguns conceitos basilares sobre a vida e obra de João Batista de La Salle. Para isso, em um primeiro momento as autoras, trazem uma breve narrativa da vida e da criação das escolas Lassalistas, instituições de ensino que tomaram conta da França no final do século XVII e início do século XVIII; e em seguida discutem a maneira como estas escolas foram organizadas e administradas, sobretudo com algumas reflexões sobre as regras de comportamento criadas por La Salle.

Continuando as discussões sobre a temática educação, os autores Izabela Maria Mazi e Mario Marcos Lopes, no capítulo 3 - Perspectivas do brincar na educação infantil: aspectos teóricos e a prática docente, debruçam-se a apresentar os resultados de uma pesquisa bibliográfica, que teve como foco a discussão do brincar nas diferentes etapas do desenvolvimento infantil por meio da abordagem de alguns jogos e brincadeiras voltados a primeira etapa da Educação Básica. Os autores enfatizam a maneira como crianças se relacionam em seu cotidiano e a forma como interagem socialmente, além de destacar os benefícios proporcionados nos primeiros anos de vida. Com isso, o artigo levanta os aspectos que envolvem o universo lúdico e o cotidiano infantil acerca de alguns teóricos, tanto da Psicologia quando da área educacional. A referida pesquisa aborda ainda, de forma simples, algumas considerações práticas e teóricas acerca dos jogos, brincadeiras e o papel do educador, sujeito fundamental neste processo. Ainda, como resultado, os autores apontam a importância do papel do lúdico, as relações sociais advindas desta prática, a construção de conceitos, desenvolvimento integral, além da vivência de maneira significativa frente aos benefícios proporcionados. Nota-se que o texto proporciona uma visão e leitura mais consciente acerca do brincar infantil, capaz de formar indivíduos críticos, participativos, e com autonomia perante as dificuldades enfrentadas.

Colaborando com a discussão, a autora Carla Regina Lopes Vitorasso Moreira no capítulo 4 - Monteiro Lobato e a inovação da literatura infantil brasileira, aponta a importância que o autor Monteiro Lobato exerceu na literatura infantil brasileira, tornando-se um marco definitivo. Muito influente e tantas vezes polêmico, trouxe uma importante reflexão para o povo brasileiro, por meio de seus livros e de sua luta para uma modernização do Brasil. Além disso, a autora mostra como a obra infantil 'Sítio do Pica Pau 
Amarelo', tornou-se tão importante para a sua época, perdurando até os dias atuais, de uma forma bastante abrangente. Nota-se por meio da leitura do texto que a influência de Monteiro Lobato foi tão grande que essa literatura acabou dividindo-se em três épocas (pré-lobatiana, lobatiana e pós-lobatiana).

Por sua vez, no capítulo 5 - Ressentimento e autonomia: uma abordagem genealógica da infância os autores Paulo Rogério da Silva e Ana Paula Peruzzi apontam que as instituições de Educação Infantil, desde a mais tenra idade, introduzem nas crianças uma produção de estereótipos que definem os elementos constituintes do 'bom' e do 'mal', do 'justo' e 'injusto' etc., bem como daqueles papéis sociais culturalmente aceitos, que modelam a economia psíquica com relação, por exemplo, à questão do gênero, do mundo do trabalho, dos bons modos, da cidadania, da moral religiosa etc. $\mathrm{O}$ fato é que a infância nunca foi ouvida a partir dela mesma, o que só reforça um preconceito socialmente produzido com relação ao mundo infantil que, ao mesmo tempo que silencia suas inquietações frente às instituições educacionais, cria um conceito hipostático, padronizado e, por isso, falso de infância. Para tentar compreender esse fenômeno padronizador, os autores tomam como apoio o pensamento de Friedrich Nietzsche (1844-1900), em particular sua obra Genealogia da Moral, que, de modo geral, parte do pressuposto que o universal nada mais é do que o particular dogmatizado num dado momento da história. A partir da abordagem genealógica de Nietzsche, o texto não só aponta o modo como a tradição modela a hegemonia de certos valores em detrimento de outros, como também de que maneira aqueles valores salutares relativos à experiência infantil são socialmente reinterpretados como nocivos pelo mundo escolar adulto.

No desenrolar da obra, a autora Liamar Tuon no capítulo 6 - Cemitérios, febre amarela e a infância interrompida (Jaboticabal - SP, 1895-1901) apresenta as origens da cidade de Jaboticabal-SP e a relação desta mesma cidade com os diferentes cemitérios criados na localidade. Dedica-se especial atenção à epidemia de febre amarela que assolou a cidade nos anos de 1896, 1897 e 1898, deixando centenas de mortos, especialmente crianças. Conforma observa-se no artigo, para análise do tema foram utilizados dados dos Recenseamentos de 1872, 1890 e 1900 do acervo do Cemitério Municipal de Jaboticabal e documentos produzidos por historiadores e memorialistas que se encontram no Museu Histórico Aloísio de Almeida de Jaboticabal. O texto demonstra através da análise de dados que apesar de morrerem muitas pessoas de febre amarela, outras doenças como diarreia e verminoses matavam muito mais do que a epidemia. As crianças eram as principais vítimas morrendo muitas vezes no próprio parto, assim como suas mães. Tantas mortes demonstram como eram precárias, as condições sanitárias da cidade, como em muitas outras do interior do Estado de São Paulo.

No capítulo 7 - Cidadania, família, direito e educação: a contribuição do judiciário na formação da criança e do adolescente, os autores Adriana Maria Risso Caires Silva, Antonio Carlos Fuzaro Junior e João Francisco Othon Teixeira investigam a importância da escola, da família e dos Juizados da Infância e Juventude na formação da criança e do adolescente, quer seja em situação de risco ou no exercício da cidadania, noções básicas ensinadas desde cedo através do projeto "Cidadania e Justiça Também se Aprendem na Escola”, idealizado pela Associação dos Magistrados Brasileiros (AMB), e desenvolvido pela Comarca de Catanduva- SP. O artigo aponta, o trabalho desenvolvido pelo Judiciário na Comarca de Catanduva (Cidadania e Justiça Também se Aprendem na Escola), idealizado pela Associação dos Magistrados Brasileiros (AMB), que busca de maneira simples conscientizar professores pais e alunos, sobre os caminhos para exercer seus direitos e a importância de cumprir seus deveres de maneira que levem à reflexão ética de cidadania e justiça, ao mesmo tempo em que apresenta a estrutura e o funcionamento do Estado, principalmente do Poder Judiciário, do Ministério Público, da Defensoria Pública, das Polícias e outros serviços públicos essenciais à conscientização do ideal de Justiça. A educação não se restringe apenas a escola, quanto maior for o número de diferentes agentes e diferentes setores envolvidos na formação dos jovens certamente teremos futuros cidadãos capazes de exercer seus direitos e deveres em 
pleno exercício da cidadania.

Seguindo o debate educacional a autora Paola Alves Martins dos Santos no capítulo 8 - Da violência velada ao silêncio rompido: as contribuições do conselho tutelar no combate ao abuso sexual contra a criança e o adolescente, relata sua experiência como conselheira tutelar, abordando a contribuição do Conselho Tutelar em face do crime de abuso sexual contra criança e adolescente. A autora ressalta que as notificações encaminhadas pelas instituições de educação ou saúde ou a própria denúncia feita diretamente ao Conselho Tutelar, é considerada às vezes a principal prova para este crime, que por precaução do abusador pode não deixar vestígios físicos. Nesse contexto, ouvir a criança e o adolescente por diferentes órgãos, não ocorre a revitimização, pois é o momento em que será rompido o silêncio. Com base nesta experiência, ressalta-se a importância do trabalho do Conselho Tutelar para validar, talvez como única prova frente ao sistema jurídico para punir o abusador e garantir a proteção à criança e ao adolescente.

No capítulo 9 - Relações de gênero, sexualidades e cinema nas trilhas de Breakfast With Scot os autores Alessandro Garcia Paulino e Cláudia Maria Ribeiro focam a formação inicial de professores/as nas temáticas de Gênero, Sexualidades e Cinema em uma universidade do sul de Minas Gerais. Utilizou-se nesse contexto a metodologia do Grupo Focal (GF) que constitui um instrumento de pesquisa qualitativa como forma de captar enunciados. Foi exibido o filme "Breakfast With Scot" (2008) cujas temáticas centrais abordaram as questões de gênero e sexualidades. Segundos os autores, para os/as participantes do Grupo Focal, ou seja, discentes dos cursos de licenciatura, foram propostas reuniões de modo a realizar discussões, levando em consideração seus saberes e discursos a respeito das temáticas supracitadas a partir dos do filme assistido. O material empírico, advindo desse procedimento de pesquisa, foi articulado com as teorizações Pós-estruturalistas e os estudos Foucaultianos, buscando operar com o desafio de realizar este trabalho por meio dessas perspectivas. Notou-se que os/as discentes participantes anseiam pelas problematizações nas temáticas de gênero e sexualidades e de que há uma necessidade da intervenção por parte da Universidade para ampliar as possibilidades de um continuo processo de formação. Por fim, o cinema possibilitou ampliar as discussões levando em consideração a educação para as imagens no processo de subjetivação dos/as participantes.

Por sua vez, no capítulo 10 - A sala de aula e os corpos que nela são permitidos existirem: o conceito de diversidade sexual a partir de um olhar sobre os saberes docentes de professoras de história os autores Hamilton Édio dos Santos Vieira, Osmar Arruda Garcia e Paulo Rennes Marçal Ribeiro, a partir da participação de quatro professoras de História com vinte e três anos de magistério na rede pública do estado de São Paulo investigam seus relatos, em que procuravam utilizar seus saberes docentes sobre o que entendiam ser diversidade sexual, quais formas de entrelaçamento entre suas experiências e como construíam corpos que escapavam da materialidade que as mesmas davam de acordo com suas reflexões sobre a existência desses mesmos corpos em salas de aula, produzidos em suas percepções de forma abjeta. Nesse sentido, apontar para uma discussão sobre a formação docente e o trato com as temáticas de gênero, sexualidade e diversidade sexual no espaço da escola e entender que existe uma sinuosa e complexa rede de saberes advindos da experiência que pouco dialoga com a formação acadêmica e disciplinar, mas que aponta a necessidade de validar esses saberes pessoais e compreender como engendram-se no cotidiano das professoras de maneira que por suas arestas possa se desconstruir esses saberes e possibilitar novos trajetos que de fato contemplem a diversidade sexual e na construção de corpos mais livres e cidadãos.

Por fim, Emerson Benedito Ferreira no capítulo 11 intitulado A polícia dos costumes: medicina, higienismo e controle da sexualidade infantil no quarto final do século XIX discute o contexto e o sentido do termo 'onanismo' propagado com pontualidade em trabalhos científicos e periódicos da segunda metade do século XIX. O termo tinha o caráter de coibir a sexualidade de crianças e adolescentes por meio do discurso da enfermidade e da degeneração dos corpos. No compêndio, busca-se de alguma forma relacionar 
tais discursos médicos oitocentistas produzidos no Brasil com o dispositivo da sexualidade cunhado por Michel Foucault. Os materiais utilizados para análise baseiam-se em Teses médicas da Faculdade de Medicina do Rio de Janeiro e da Bahia, bem como o periódico denominado 'A Mai de Família', em um recorte que compreenderá os anos de 1834 a 1897.

Nota-se que a presente obra consolida-se como mais um veículo de expressão acadêmica que rompe com os liames estritamente teóricos, para apresentar contextos do cotidiano e da educação brasileira, em uma sociedade secular que luta para ultrapassar amarras paradigmáticas, indesejáveis ao avanço do pensamento que concebe a educação como um processo igualitário, justo e acessível.

Conforma aponta a pesquisadora Maria Betanea Platzer, responsável pelo texto de Introdução da obra, “a reunião de assuntos instigantes e desafiadores é um convite para que possamos adentrar nesse complexo universo educacional, em um movimento de compreendê-lo em sua amplitude e diferentes dimensões. Verificamos, no decorrer deste livro, diferentes vozes que, a partir de olhares diversos, culminam na busca pela educação de crianças, jovens e adultos”.

Convidamos o leitor a desfrutar uma leitura riquíssima, diversificada, abrangente, prazerosa e reflexiva, um verdadeiro encontro nas fronteiras do conhecimento, nos temas debatidos.

\section{REFERÊNCIA}

FERREIRA, Emerson Benedito; LOPES, Mario Marcos (Orgs.). Pesquisas em educação: escola, infância e sexualidade. São Carlos: Pedro \& João Editores, 2016. 